\title{
Исследование сорбционной активности фармакофрорсодержащих пектинов по отношению к катионам кобальта (II)
}

\author{
Сагитова А.Ф. ${ }^{1}$, Куковинец О.С. ${ }^{1}$, Мударисова Р.Х. ${ }^{2}$ \\ ${ }^{\prime}$ ФББОУ ВО Башкирский государственный университет, инженерный факультет, Уфа \\ ${ }^{2}$ Уфимский институт химии УФИЦ РАН, Уфа
}

Поступила в редакцию 16.02.2018 г.

DOI: https://doi.org/10.17308/sorpchrom.2018.18/560

Рассмотрены закономерности сорбции ионов кобальта (II) нативным и модифицированным органическими фармакофорами (салициловая, антраниловая, никотиновая кислоты) пектинами. Определено влияние различных факторов (кислотность, температура, модуль раствор/сорбент) на процесс распределения ионов кобальта (II) в гетерофазной системе полисахаридный сорбент - водный раствор. Исследован механизм кинетики сорбции ионов металла (II) биосорбентами. Определено влияние природы биосорбентов на термодинамику распределения ионов кобальта (II). Установлено, что сорбция ионов $\mathrm{Co}^{2+}$ модифицированными пектиновыми сорбентами описывается уравнением Ленгмюра.

Ключевые слова: яблочный пектин, фармакофоры, ионы кобальта (II), сорбция, биосорбент, кинетика, изотермы.

\section{Study of the sorption activity of pharmacophore-containing pectins with respect to cations of cobalt (II)}

\author{
Sagitova A.F., Kukovinets O.S., Mudarisova R.Kh. \\ ${ }^{1}$ Bashkir State University, Ufa \\ ${ }^{2}$ Ufa Institute of Chemistry of the Russian Academy of Sciences, Ufa
}

\begin{abstract}
The regularities of sorption to ions of cobalt (II) by native and modified organic pharmacophore (salicylic, antranilic, nicotinic acids) pectins are considered. Modification of pectin by pharmacophore reduces the time to reach equilibrium, depending on the nature of the organic component while maintaining high sorption capacity. The influence of various factors (acidity, temperature, solution/sorbent modulus) on the distribution ions of cobalt (II) in the heterophasic system of the polysaccharide sorbent-aqueous solution was determined. It was found that the optimum $\mathrm{pH}$ of the medium for extracting cobalt (II) ions from aqueous solutions, at which the maximum of sorption is reached, is a pH close to neutral. With an increase in the solution/sorbent module from 50 to $1000 \mathrm{l} / \mathrm{kg}$, a decrease in the degree of extraction of $\mathrm{Co}^{2+}$ ions by pharmacophore-containing pectins is observed. When studying the effect of temperature on the sorption process, it was found that with increasing temperature, the degree of extraction of cobalt ions with pectin-containing sorbents is markedly reduced. The mechanism of sorption kinetics of metal ions (II) by biosorbents is studied. Sorption process of interaction of metal (II) cations with functional groups of pectin/pharmacophorecontaining pectin involves three successive stages of mass transfer of sorbate on biosorbents: external diffusion mass transfer, intradiffusion mass transfer and ion exchange process. The influence of the nature of bio-
\end{abstract}


sorbents on the thermodynamics of the distribution of cobalt (II) ions is determined. It was found that sorption of $\mathrm{Co}^{2+}$ ions by modified pectin sorbents is described by the Langmuir equation. therms.

Keywords: apple pectin, pharmacophores, ions of cobalt (II), sorption, biosorbent, kinetic, iso-

\section{Введение}

Заметный интерес, проявляемый в последние годы к сорбции ионов различных металлов полисахаридными сорбентами, объясняется важностью этих соединений для пищевой промышленности, фармакологии и медицины, токсикологии, экологического контроля [1-3]. Среди большого разнообразия биосорбентов особое внимание привлекают пектины - полисахариды растительного происхождения, характеризующиеся высокой биологической активностью $[4,5]$. Несмотря на то, что пектиновые сорбенты обладают неоспоримыми преимуществами, такими как дешевизна, доступность, биоразлагаемость в окружающей среде, высокая сорбционная емкость, крайне важной является задача создания новых высокоэффективных материалов, сочетающих в себе полезные свойства компонентов модифицированного сорбента с сохранением высокой сорбционной способности $[6,7]$.

В настоящее время в литературе имеются различные взгляды в отношении выбора сорбционной модели, описывающей сорбционный процесс [8]. При этом описание экспериментальных изотерм проводится с помощью различных моделей сорбции, таких как модель Ленгмюра, Фрейндлиха и др. [9]. Биосорбенты полисахаридной природы, несмотря на сложность в изучении механизма сорбционных процессов, представляют несомненный практический и научный интерес.

Целью настоящей работы является установление закономерностей распределения ионов Со (II) в гетерофазной системе «водный раствор хлорида кобальта (II) яблочный пектин, модифицированный биологически активными органическими кислотами (никотиновая (НК), антраниловая (АК) и салициловая кислоты (СК), обладающие широким спектром фармакологической активности), выявление влияния различных факторов на процесс сорбции и получение экспериментальных моделей взаимодействия биосорбентов с катионами кобальта (II).

\section{Эксперимент}

В качестве сорбента выбран яблочный пектин (П) товарной марки Unipectine ХРP 240 с молекулярной массой $26000 \mathrm{Da}$ и степенью этерифицирования 66\%. Источником ионов кобальта (II) выбран хлорид кобальта $\mathrm{CoCl}_{2} \cdot 6 \mathrm{H}_{2} \mathrm{O}$ марки «х.ч.». В качестве модифицирующих агентов использовали никотиновую, антраниловую и салициловую кислоты марки «чда». Общая методика получения фармакофорсодержащих пектинов: растворяют 1 г полисахарида (5.68 осново-ммоль) в $20 \mathrm{~cm}^{3}$ воды с $\mathrm{pH} 7-7.1$ и 5.68 осново-ммоль фармакофора суспензируют в $20 \mathrm{~cm}^{3}$ воды и доводят pH до 7-7.1. К раствору полисахарида при интенсивном перемешивании прикапывают раствор фармакофора при температуре $25^{\circ} \mathrm{C}$ и выдерживают 4 часа. По окончании реакции продукт выделяют осаждением ацетоном, переосаждают в спирт, осадок отделяют и промывают три раза спиртом, затем диэтиловым эфиром и высушивают в вакууме. Полученные продукты проанализированы методами ИК-, УФспектроскопии, вискозиметрией, поляриметрией и элементным анализом [10]. Методами мольных отношений установлен состав соединений равный 1:1. Элементный состав образцов представлен в таблице 1. 
Таблица 1. Элементный состав фармакофорсодержащих пектинов

\begin{tabular}{|c|c|c|c|c|c|c|}
\hline Образец & $\mathrm{C}_{\text {эксп }} \%$ & $\mathrm{H}_{\text {эксп }} \%$ & $\mathrm{~N}_{\text {эксп }} \%$ & $\mathrm{C}_{\text {теор }} \%$ & $\mathrm{H}_{\text {теор }}, \%$ & $\mathrm{~N}_{\text {теор }} \%$ \\
\hline П-АК & 46.01 & 5.21 & 4.95 & 44.40 & 4.70 & 3.45 \\
\hline П-СК & 47.22 & 4.97 & - & 46.15 & 4.61 & - \\
\hline П-НК & 44.79 & 4.80 & 5.44 & 42.90 & 4.20 & 3.59 \\
\hline
\end{tabular}

Изучение процесса сорбции ионов кобальта (II) проводили в статических условиях из водных растворов хлорида кобальта (II) при перемешивании и термостатировании $(298$ К). Для получения кинетических кривых сорбции в серию пробирок $\left(\mathrm{V}=20 \mathrm{~cm}^{3}\right)$ помещали навески сорбента $(\mathrm{m})$ по 0.1 г, заливали их $2 \mathrm{~cm}^{3}$ водного раствора хлорида кобальта (II) и выдерживали от 5 до 60 минут. Начальная концентрация $\left(\mathrm{C}_{0}\right)$ раствора хлорида кобальта (II) составляла $10^{-1}$ моль/дм ${ }^{3}$. Через каждые 15 минут раствор отделяли от сорбента фильтрованием и определяли в нем текущую концентрацию ионов кобальта $\left(\mathrm{C}_{\tau}\right)$ методом титриметрии. В коническую колбу с притертой пробкой вместимостью $25 \mathrm{~cm}^{3}$ вносят $1 \mathrm{~cm}^{3}$ раствора индигокармина с молярной концентрацией эквивалента $5 \cdot 10^{-3}$ моль/дм $\mathrm{m}^{3}$, образец объемом $0.5 \mathrm{~cm}^{3}$ и прибавляют $5 \mathrm{~cm}^{3} 6 \mathrm{M}$ соляной кислоты. Титруют раствором бромата калия с молярной концентрацией эквивалента $5 \cdot 10^{-3}$ моль/дм ${ }^{3}$ до перехода синей окраски раствора в желтую. Остаточную концентрацию хлорида кобальта (II) рассчитывают по золотому правилу аналитической химии: $\mathrm{C}\left(\mathrm{KBrO}_{3}\right) \cdot \mathrm{V}\left(\mathrm{KBrO}_{3}\right)=\mathrm{C}\left(\mathrm{CoCl}_{2}\right) \cdot \mathrm{V}\left(\mathrm{CoCl}_{2}\right)$ [11]. Сорбционную емкость $\left(\mathrm{A}_{\tau}\right)$ сорбентов в каждый данный момент времени рассчитывали по формуле: $\mathrm{A}_{\tau}=\left(\mathrm{C}_{0}-\mathrm{C}_{\tau}\right) \cdot \mathrm{V} / \mathrm{m}[12]$.

Для исследования влияния $\mathrm{pH}$ среды на эффективность извлечения ионов кобальта необходимую величину $\mathrm{pH}$ создавали $0.1 \mathrm{M} \mathrm{H}_{2} \mathrm{SO}_{4}$ и $0.1 \mathrm{M} \mathrm{NaOH}$ и контроли-

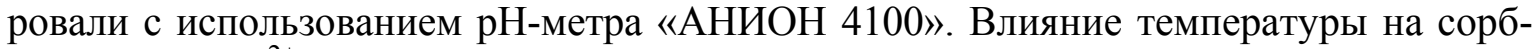
цию ионов $\mathrm{Co}^{2+}$ рассматривали в интервале от 273 до $333 \mathrm{~K}$ при перемешивании и термостатировании при определенной температуре. По окончании опытов раствор отделяли от сорбента фильтрованием и определяли в нем текущую концентрацию ионов кобальта (II). Влияние модуля раствор/сорбент на сорбцию ионов $\mathrm{Co}^{2+}$ исследовали в интервале от 50 до 1000 дм $^{3} /$ кг. Объем раствора, соответственно, варьировали от 5 до $100 \mathrm{~cm}^{3}$ и выдерживали в течение 60 мин при перемешивании при температуре 293 К. Константы кислотной диссоциации определяли методом потенциометрического титрования [13].

\section{Обсуждение результатов}

При оценке эффективности сорбентов большое значение имеют величина сорбционной емкости и время достижения сорбционного равновесия. Кинетические исследования показали, что сорбционное равновесие при извлечении катионов металла нативным пектином достигается в течение 60 мин, тогда как в случае фармакофорсодержащего пектинового сорбента равновесие устанавливается в течение 4045 мин (табл. 2), что может быть обусловлено как появлением новых функциональных групп, способных эффективно связывать ионы металла, так и повышением доступности активных центров биосорбента. По сорбционной емкости сорбенты располагаются в следующий ряд: П-СК $>$ П-НК> П-АК. Наибольшей сорбционной емкостью обладает образец П-СК (табл. 1), что, вероятно, связано с его наибольшей кислотностью.

Для выяснения механизма взаимодействия катионов кобальта (II) с функциональными группами пектина/фармакофорсодержащих пектинов получены кинетические кривые сорбции (рис. 1). Как видно, в начальный период сорбции количество сорбирующегося катиона металла (II) П/ФП увеличивается очень быстро, затем, по

Сагитова и др. / Сорбционные и хроматографические процессы. 2018. Т. 18. № 4 
мере приближения к равновесию, сорбционный процесс замедляется. Резкий подъем скорости в начале сорбции может указывать как на быстрый массоперенос катионов кобальта (II) из раствора к активным центрам сорбентов [14], так и на быстрое химическое связывание катионов с активными центрами сорбентов на их поверхности $[15]$.

Таблица 2. Сорбционные характеристики биосорбентов по отношению к ионам кобальта (II)

\begin{tabular}{|c|c|c|c|c|}
\hline Биосорбент & $\begin{array}{c}\text { Степень } \\
\text { извлечения } \\
\text { ионов } \mathrm{Co}^{2+}, \%\end{array}$ & $\begin{array}{c}\text { Сорбционная } \\
\text { емкость, ммоль/Г }\end{array}$ & $\begin{array}{c}\text { Время достижения } \\
\text { равновесия, мин }\end{array}$ & $\mathrm{pK}_{\mathrm{a}}$ \\
\hline$\Pi$ & 79.5 & 1.89 & 60 & 4.50 \\
\hline П-СК & 89.1 & 1.94 & 45 & 2.45 \\
\hline П-НК & 87.2 & 1.93 & 45 & 4.06 \\
\hline П-АК & 86.7 & 1.92 & 40 & 3.90 \\
\hline
\end{tabular}

Для выяснения механизма взаимодействия катионов кобальта (II) с функциональными группами пектина/фармакофорсодержащих пектинов получены кинетические кривые сорбции (рис. 1). Как видно, в начальный период сорбции количество сорбирующегося катиона металла (II) П/ФП увеличивается очень быстро, затем, по мере приближения к равновесию, сорбционный процесс замедляется. Резкий подъем скорости в начале сорбции может указывать как на быстрый массоперенос катионов кобальта (II) из раствора к активным центрам сорбентов [14], так и на быстрое химическое связывание катионов с активными центрами сорбентов на их поверхности [15].

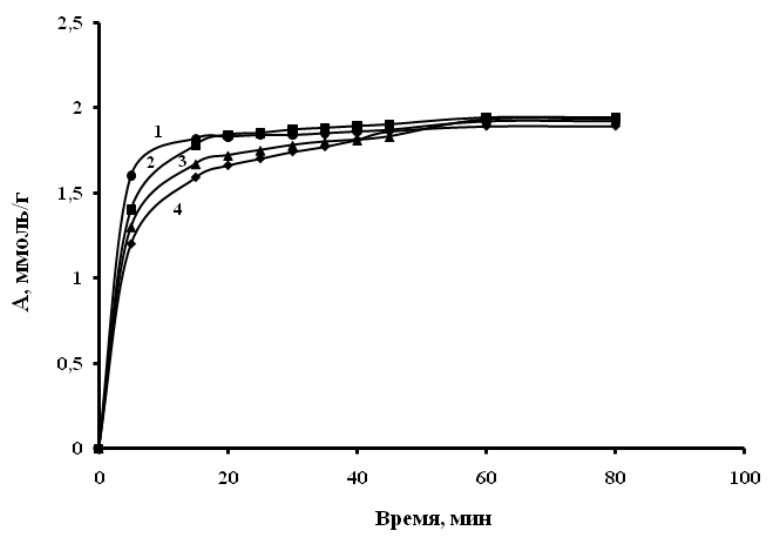

Рис. 1. Интегральные кинетические кривые сорбции ионов кобальта (II) сорбентами: П-АК (1), П-СК (2), П-НК (3), П (4).

Все кинетические кривые описываются уравнением для внешнедиффузионных процессов: $\ln (1-\mathrm{F})=-\Gamma \cdot(\mathrm{t})$, где $\mathrm{F}$ - скорость достижения равновесия, рассчитываемая по формуле $\mathrm{F}=\mathrm{A}_{\mathrm{t}} / \mathrm{A}_{\infty}, \mathrm{A}_{\mathrm{t}}$ - количество сорбированного катиона металла в момент времени $\mathrm{t}, \mathrm{A}_{\infty}$ - количество сорбированного катиона металла в состоянии равновесия; $\Gamma$ - некоторая величина, постоянная для данных условий; $\mathrm{t}$ - время.

Зависимость $-\ln (1-\mathrm{F})=\mathrm{f}(\mathrm{t})$ приведена на рис. 2. Обнаружено, что только на начальных участках зависимости наблюдается прямолинейный характер функции. В дальнейшем, кинетические кривые не выдерживают критерия чисто «внешнедиффузионного» механизма. Данный факт свидетельствует о том, что сорбционный процесс на биосорбентах протекает в смешаннодиффузионном режиме, т.е. контролируется одновременно внешней и внутренней диффузией. 


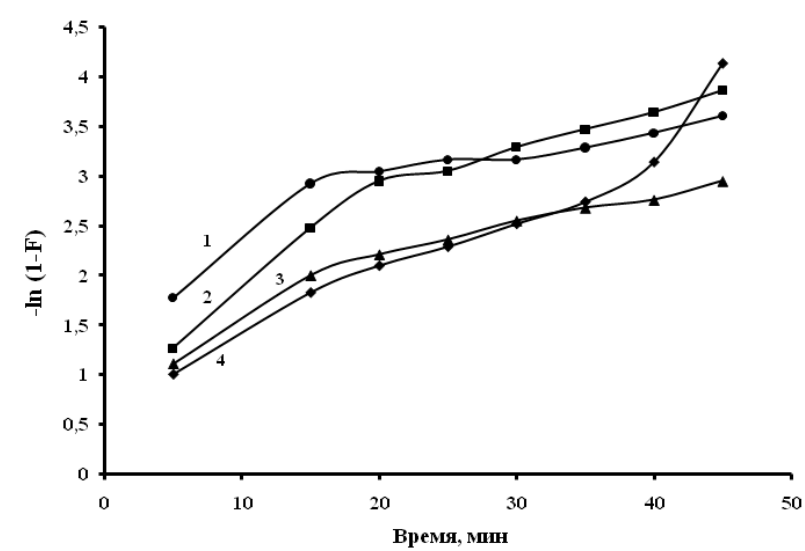

Рис. 2. Анаморфозы кинетических кривых сорбции ионов кобальта (II) сорбентами: П-АК (1), П-СК (2), П-НК (3), П (4) в координатах уравнений, описывающих внешнедиффузионные процессы

Для проверки соответствия кинетических кривых модели внутридиффузионной кинетики была проведена обработка кинетических кривых в координатах $A_{t}-t^{1 / 2}$. Результаты показывают (рис. 3), что по мере увеличения продолжительности контактирования П/ФП с катионами металла (II), количество сорбированных катионов возрастает пропорционально величине $\mathrm{t}^{1 / 2}$ вплоть до достижения равновесия. Полученные зависимости являются мультилинейными и не выходят из начала координат, что свидетельствует о многостадийном взаимодействии сорбата с сорбентом.

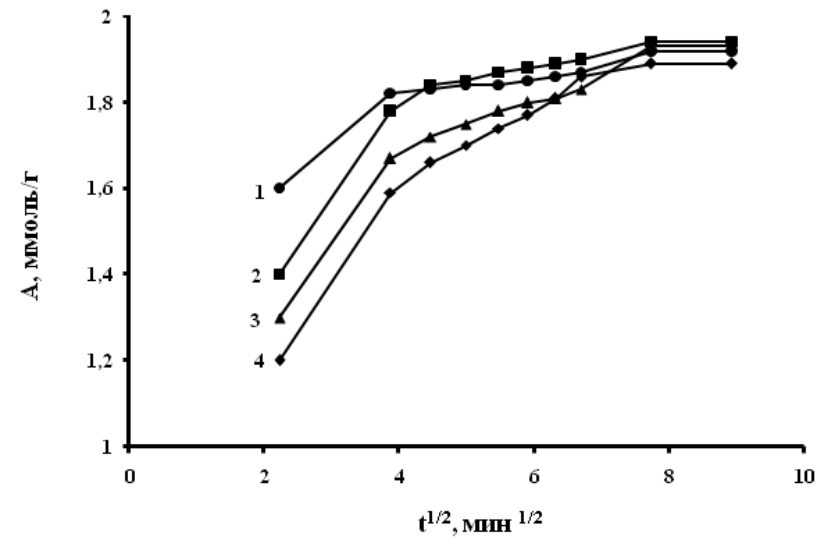

Рис. 3. Анаморфозы кинетических кривых сорбции ионов кобальта (II) сорбентами: П-АК (1), П-СК (2), П-НК (3), П (4) в координатах уравнений, описывающих внутридиффузионные процессы

В процессе обмена, происходящего между функциональными группами П/ФП с катионами кобальта (II), можно выделить три последовательных стадии массопереноса сорбата на сорбентах. Первый крутой участок характеризует диффузию катионов кобальта (II) из объема раствора через внешний диффузионный слой (неподвижную водяную пленку, образующуюся при контакте сорбентов с раствором) к поверхности частиц нативного и модифицированных пектинов (внешнедиффузионный массоперенос). Второй участок относится к диффузии катионов кобальта (II) в частицах П/ФП к активным центрам (внутридиффузионный массоперенос). Вытесняющий катион перемещается сквозь слой уже адсорбированных поверхностью сорбента катионов вглубь частиц П/ФП через систему пор и капилляров. Третий завершающий пологий участок отражает ионообменный процесс. 
Следующим этапом обработки кинетических кривых являлось применение моделей, позволяющих выявить вклад химической стадии в процесс сорбции. Одними из широко используемых моделей для описания сорбции в системе «раствор твердое тело» являются модели псевдо-первого и псевдо-второго порядка [16], которые представлены в линейной форме в уравнениях (1) и (2), соответственно:

$$
\begin{aligned}
A_{t} & =A_{\infty} \cdot\left(1-e^{-k}{ }_{1}^{t}\right), \\
A_{t} & =t /\left(1 / k_{2} \cdot A_{\infty}{ }^{2}\right)+1 / A_{\infty},
\end{aligned}
$$

где $\mathrm{A}_{\mathrm{t}}$ и $\mathrm{A}_{\infty}$ - количество сорбированного катиона металла на единицу массы сорбента в момент времени $\mathrm{t}$ и в состоянии равновесия; $\mathrm{k}_{1}$ - константа скорости сорбции модели псевдо-первого порядка, мин ${ }^{-1} ; \mathrm{k}_{2}$ - константа скорости сорбции модели псевдо-второго порядка, г.(ммоль $\cdot$ мин $)^{-1}$. На рис. 4 и 5 представлены зависимости $\mathrm{f}(\mathrm{t})=\lg \left(\mathrm{A}_{\infty}-\mathrm{A}_{\mathrm{t}}\right)$ и $\mathrm{f}(\mathrm{t})=\mathrm{t} / \mathrm{A}_{\mathrm{t}}$. Видно, что кинетические уравнения псевдо-первого порядка удовлетворительно описывают экспериментальные данные только на начальных стадиях процесса, а модель псевдо-второго порядка во всем изучаемом интервале времени.

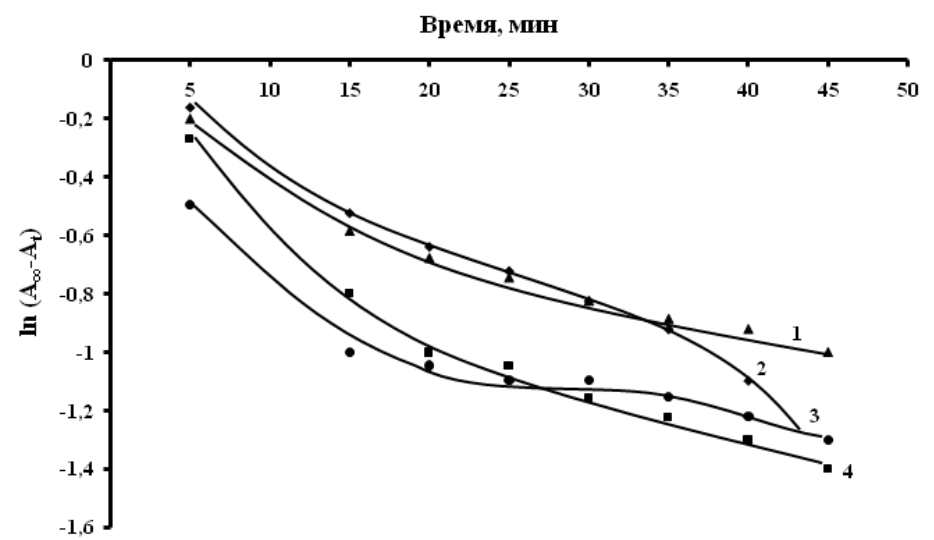

Рис. 4. Анаморфозы кинетических кривых сорбции ионов кобальта (II) сорбентами: П (1), П-НК (2), П-СК (3), П-АК (4) в координатах уравнений, описывающих реакции псевдо-первого порядка

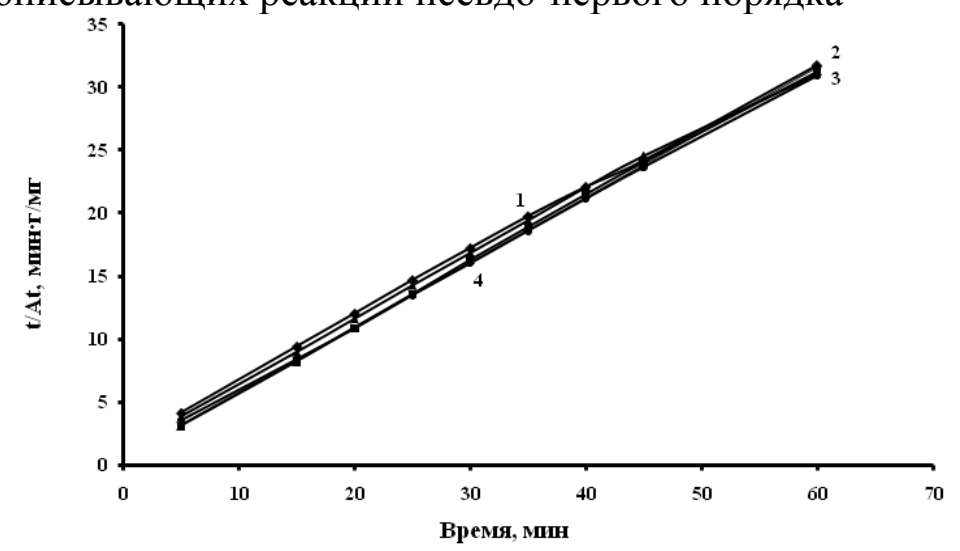

Рис. 5. Анаморфозы кинетических кривых сорбции ионов кобальта (II) сорбентами: П-АК (1), П-СК (2), П-НК (3), П (4) в координатах уравнений, описывающих реакции псевдо-второго порядка

Имеющиеся сравнительные данные (табл. 3) свидетельствуют о хорошей корреляции уравнения псевдо-второго порядка. Соответствие опытных данных кинетическому уравнению псевдо-второго порядка указывает на то, что взаимодействие между сорбатом и функциональной группой сорбента подчиняется закону действующих масс для реакций второго порядка (скорость взаимодействия пропорциональна произведению концентраций двух реагирующих веществ). 
Таблица 3. Параметры обработки уравнений псевдо-первого и псевдо-второго порядка

\begin{tabular}{|c|c|c|}
\hline \multirow{2}{*}{ Биосорбент } & \multicolumn{2}{|c|}{ Коэффициент корреляции, $\mathrm{R}^{2}$} \\
\cline { 2 - 3 } & Уравнение псевдо-первого порядка & Уравнение псевдо-второго порядка \\
\hline П & 0.945 & 0.998 \\
\hline П-СК & 0.869 & 0.999 \\
\hline П-НК & 0.852 & 0.997 \\
\hline П-АК & 0.725 & 0.999 \\
\hline
\end{tabular}

Таким образом, обработка экспериментальных данных формальными кинетическими уравнениями показала, что в ходе процесса сорбции наблюдается суммарный эффект диффузии и химической реакции.

Одним из важных параметров, влияющих на глубину протекания сорбции, является кислотность среды. Выявлено что, оптимальным рН среды для извлечения ионов кобальта (II) из водных растворов, при котором достигается максимум сорбции, является $\mathrm{pH}$, близкий к нейтральным (табл. 4). При увеличении модуля раствор/сорбент с 50 до $1000 \mathrm{дm}^{3} /$ кг наблюдается снижение степени извлечения ионов $\mathrm{Co}^{2+}$ фармакофорсодержащими пектинами (табл. 4). При изучении влияния температуры на сорбционный процесс выявлено, что с ростом температуры степень извлечения ионов кобальта пектинсодержащими сорбентами заметно снижается (табл. 5). Энергетические характеристики сорбции $\Delta \mathrm{G}^{\circ}$ и $\Delta \mathrm{H}^{\circ}$ имеют отрицательные величины, что свидетельствует о самопроизвольности протекающих процессов и их экзотермичности.

Таблица 4. Влияние $\mathrm{pH}$ и модуля раствор/сорбент на сорбцию кобальта (II) пектином/фармакофосодержащими пектинами

\begin{tabular}{|c|c|c|}
\hline Биосорбент & $\mathrm{pH}$ & Модуль раствор/сорбент, л/кг \\
\hline$\Pi$ & $4.0 \pm 0.5$ & $200(79.5 \%)$ \\
\hline П-СК & $6.5 \pm 0.5$ & $50(95.1 \%)$ \\
\hline П-АК & $6.0 \pm 1.0$ & $50(89.2 \%)$ \\
\hline П-НК & $6.0 \pm 1.0$ & $50(94.0 \%)$ \\
\hline
\end{tabular}

Таблица 5. Термодинамические параметры сорбции ионов кобальта (II) П/ФП

\begin{tabular}{|c|c|c|c|c|c|}
\hline Биосорбент & $\mathrm{T}, \mathrm{K}$ & $\alpha, \%$ & $\Delta \mathrm{H}^{\mathrm{o}}{ }_{298}$, кДж/моль & $\begin{array}{c}\Delta \mathrm{S}^{\mathrm{o}}{ }_{298,} \\
\text { Дж/моль } \cdot \mathrm{K}\end{array}$ & $\begin{array}{c}\Delta \mathrm{G}^{\mathrm{o}}{ }_{298,}, \\
\text { КДж/моль }\end{array}$ \\
\hline$\Pi$ & $\begin{array}{c}0 \\
20 \\
40 \\
60\end{array}$ & $\begin{array}{l}59.0 \\
79.5 \\
42.2 \\
38.1\end{array}$ & $-7.5 \pm 0.1$ & $-50.5 \pm 0.2$ & $-7.9 \pm 0.1$ \\
\hline П-СК & $\begin{array}{c}0 \\
20 \\
40 \\
60\end{array}$ & $\begin{array}{l}95.5 \\
89.1 \\
76.1 \\
61.4\end{array}$ & $-6.9 \pm 0.1$ & $-45.3 \pm 0.1$ & $-6.9 \pm 0.1$ \\
\hline П-НК & $\begin{array}{c}0 \\
20 \\
40 \\
60\end{array}$ & $\begin{array}{l}78.7 \\
87.2 \\
51.0 \\
29.8\end{array}$ & $-14.0 \pm 0.1$ & $-71.4 \pm 0.2$ & $-7.7 \pm 0.1$ \\
\hline П-АК & $\begin{array}{c}0 \\
20 \\
40 \\
60\end{array}$ & $\begin{array}{l}90.3 \\
86.7 \\
74.5 \\
65.5\end{array}$ & $-4.5 \pm 0.1$ & $-37.6 \pm 0.1$ & $-6.9 \pm 0.1$ \\
\hline
\end{tabular}


Проведена математическая обработка изотерм сорбции ионов кобальта (II) на соответствие известным теоретическим моделям Ленгмюра и Фрейндлиха (табл. 6). Установлено, что сорбция ионов металла на исследуемых биосорбентах описывается наилучшим образом эмпирическим уравнением Ленгмюра, описывающего сорбционный процесс, протекающий на поверхности с энергетически эквивалентными сорбционными центрами [10].

Таблица 6. Параметры обработки уравнения Ленгмюра

\begin{tabular}{|c|c|c|c|c|}
\hline Биосорбент & $1 /\left(\mathrm{A}_{\infty} \mathrm{K}\right), 10^{2}$ & $\mathrm{R}$ & $\mathrm{A}_{\infty}$, ммоль $/ \Gamma$ & $\mathrm{K}_{\mathrm{D}}$, л/моль \\
\hline Пектин & $1.53 \pm 0.1$ & 1 & 0.145 & 0.46 \\
\hline П-СК & $5.40 \pm 0.2$ & 1 & 0.169 & 0.11 \\
\hline П-НК & $8.69 \pm 0.1$ & 1 & 0.192 & 0.06 \\
\hline П-АК & $3.22 \pm 0.2$ & 1 & 0.172 & 0.18 \\
\hline
\end{tabular}

\section{Заключение}

Исследованы сорбционные свойства фармакофорсодержащих пектиновых биосорбентов. Модификация пектина фармакофорами сокращает время достижения равновесия в зависимости от природы органической компоненты при сохранении высокой сорбционной способности. Рассмотрен механизм кинетики сорбции катионов кобальта (II) нативным и модифицированными пектинами. Сорбционный процесс взаимодействия катионов металла (II) с функциональными группами П/ФП включает три последовательных стадии массопереноса сорбата на биосорбентах: внешнедиффузионный массоперенос, внутридиффузионный массоперенос и ионообменный процесс. Данный факт свидетельствует о том, что процесс сорбции на модифицированных биосорбентах протекает в смешаннодиффузионном режиме. Подобраны оптимальные условия сорбции для достижения максимальной степени извлечения металла (рН 4-6, Т 0-20 ${ }^{\circ}$, модуль раствор/сорбент 50 дм³/кг). Определено влияние природы биосорбентов на термодинамику распределения ионов кобальта (II) в гетерофазной системе полисахаридный сорбент - водный раствор. Установлено, что сорбция ионов кобальта полисахаридными материалами представляет собой экзотермический процесс, который можно рассматривать как обратимую хемосорбцию ионов кобальта за счет сольватации и комплексообразования с участием сорбционных центров сорбента и молекул растворителя (воды). Установлено, что сорбция ионов кобальта (II) на исследуемых сорбентах описывается наилучшим образом эмпирическими уравнениями Ленгмюра.

\section{Список литературы}

1. Андреева Е.Ю., Дмитриенко С.Г., Золотов Ю.А. // Успехи химии. 2012. Т. 81. № 5. C. 397.

2. Хотимченко М.Ю. Автореф. дисс. д-ра медицинских наук. Владивосток. 2011. 327 с.

3. Решетников В.И. // Химикофармачевтический журнал. 2003.Т. 37. № 5. C. 28-32.

4. Левченко Б.Д. Электротехнология пектиновых веществ. Тезисы докл. 4 н.-т. Сем.K. 1993. c. 30.

5. Мыкоц Л.П., Романцова Н.А., Гущина А.В. // Фундаментальные исследования. 2013. № 3. C. 197-200.
6. Jakobik-Kolon A., Bok-Badura J., Karon K., Mitko K., Milewski A. // Carbohydrate Polymers. 2017. Vol. 169. pp. 213-219.

7. Cataldo S., Cavallaro G., Gianguzza A., Lazzara G. et al. // Journal of Environmental Chemical Engineering. 2013. Vol. 1. Issue 4. pp. 1252-1260.

8. Никифорова T.Е. Диссертация на соискание ученой степени д-ра химических наук. Иваново. 2014. 365c.

9. Соловцова О.В.. Автореф. дис. канд. хим. наук. М.: Инст. физической химии и электрохимии им. А.Н. Фрумкина РАН. 2009. $26 \mathrm{c}$. 
10. Куковинец О.С., Мударисова Р.Х., Володина В.П., Тарасова А.В. и др. // Химия природных соединений. 2014. № 1. С. 48-51.

11. Коренман И.М. Новые титриметрические методы. М. Химия, 1983. 173 с.

12. Фролов Ю.Г. Курс коллоидной химии. Поверхностные явления и дисперсные системы. Учебник для вузов. 2-е изд. М. Химия. 1988. $464 \mathrm{c}$.

13. Лурье Ю. Ю. Справочник по аналитической химии. 1989. М. ИД «Альянс». 2007. 448 c.

\section{References}

1. Andreeva E.Y., Dmitrienko S.G, Zolotov Y.A., The success of chemistry, 2012, Vol. 81, No 5, pp. 397.

2. Khotimchenko M.Y. Author's abstract. diss. Doctor of Medical Sciences, Vladivostok, 2011, 327 p.

3. Reshetnikov V.I., Chemical and pharmaceutical magazine, 2003, Vol. 37, No 5, pp. 2832.

4. Levchenko B.D. Electrotechnology of pectic substances. Theses dokl. 4 n.-. Sem.-K. 1993, p. 30.

5. Mykoz L.P., Romantsova N.A., Gushchina A.V., Fundamental research, 2013, No 3, pp. 197-200.

6. J-Kolon A., B-Badura J., Karon K., Mitko K., Milewski A., Carbohydrate Polymers, 2017, Vol. 169, pp. 213-219. doi.org/10.1016/j.carbpol.2017.03.095.

7. Cataldo S., Cavallaro G., Gianguzza A., Lazzara G., et al., Journal of Environmental Chemical Engineering, 2013, Vol. 1, Issue 4, pp. 1252-1260. doi.org/10.1016/ j.jece.2013.09.012.

8. Nikiforova T.E. Thesis for the degree of Doctor of Chemical Sciences, Ivanovo, 2014, $365 \mathrm{p}$.

Сагитова Алина Фаиловна - соискатель ученой степени к.Х.н., Башкирский государственный университет, Уфа

Мударисова Роза Ханифовна - к.х.н., с.н.с., Уфимский институт химии РАН, Уфа

Куковинец Ольга Сергеевна - д.х.н., профессор кафедры технической химии и материаловедения, инженерный факультет, Башкирский государственный университет, Уфа
14. Ho Y.-S., Ng J.C.Y., McKay G.M. // Separation Purification Methods. 2000. Vol. 29. No 2. pp. 189-232.

15. Lazaridis N.K., Karapantsios D., Georgantas D. // Water Research. 2003. Vol. 37. pp. 3023-3033.

16. Cheung W.H., Ng J.C.Y., McKay G. // J. Chem. Technol. Biotechnol. 2003. Vol. 78. No 5. pp. 562-571.

9. Solovtsova O.V. Author's abstract. dis. Cand. chem. sciences, M., Inst. Physical Chemistry and Electrochemistry. A.N. Frumkin of the Russian Academy of Sciences, 2009, 26 p.

10. Kukovinets O.S., Mudarisova P.Kh., Volodina V.P, Tarasova A.V., et al., Chemistry of natural compounds, 2014, No 1, pp. 48-51.

11. Korenman I.M.,New titrometric metohds, M., Chemistry, 1983, 173 p.

12. Frolov Y.G. Course of colloid chemistry. Surface phenomena and disperse systems. Textbook for high schools. 2 nd ed. M., Chemistry, 1988, $464 \mathrm{p}$.

13. Lurie Y.Y. Handbook of Analytical Chemistry. 1989. M., Publishing house "Alliance", 2007, $448 \mathrm{p}$.

14. Ho Y.-S., Ng J.C.Y., McKay G.M., Separation Purification Methods, 2000, Vol. 29, No 2, pp. 189-232.

15. Lazaridis N.K., Karapantsios D., Georgantas D., Water Research, 2003, Vol. 37, pp. 3023-3033.

16. Cheung W.H., Ng J.C.Y., McKay G., J.Chem.Technol.Biotechnol., 2003, Vol. 78, No 5, pp. 562-571.

Sagitova Alina F. - candidate of chemical sciences degree, Bashkir State University, Ufa

Mudarisova Roza Kh. - Candidate of Chemical Sciences, senior researcher, Ufa Institute of Chemistry RAS, Ufa

Kukovinets Olga S. - Doctor of Chemical Sciences, Professor of the Department of Technical Chemistry and Materials Science, Faculty of Engineering, Bashkir State University, Ufa 